\title{
AS PERCEPÇÕES AMBIENTAIS DE PESCADORES E MARISQUEIRAS ACERCA DA DIVISÃO SEXUAL DE TRABALHO NA PESCA EM PIRAMBU/SE
}

\author{
Camilla Gentil Santana ${ }^{1}$
}

\section{RESUMO}

A pesca é uma atividade antiquíssima. Inicialmente com caráter de subsistência, passou por um período de escambo, no qual os recursos pesqueiros serviam como moeda de troca para obtenção de produtos agrícolas. Ao longo dos tempos, com o surgimento de comunidades, vilas e cidades, o homem desenvolveu a comercialização destes recursos. No Brasil, disseminou-se rapidamente, em diversas regiões, por possuir uma costa marítima que se estende por $8,5 \mathrm{mil} \mathrm{km}$. Em Pirambu/SE, temos a pesca como a principal atividade econômica do município até os dias de hoje e, como em outras comunidades pesqueiras, vê-se uma forte divisão sexual de trabalho. Por esse motivo, objetivou-se verificar as percepções ambientais de pescadores e marisqueiras do município de Pirambu/SE sobre a divisão sexual de trabalho vigente na estrutura pesqueira do município. Para tanto, utilizou-se uma abordagem qualitativa, com a realização de entrevistas semiestruturadas. Após análise dos resultados, conclui-se que a divisão de trabalho é fortemente delimitada, porém não há uma subordinação do trabalho feminino e sim uma naturalização das relações.

Palavras-chave: Percepção Ambiental. Divisão Sexual de Trabalho. Atividade Pesqueira.

${ }^{1}$ Mestre em Desenvolvimento e Meio Ambiente - PRODEMA/UFS. Professora da rede pública estadual de Sergipe. Email: camillagentil@yahoo.com.br 


\section{ABSTRACT}

Fishing is an ancient activity. Initially subsistence character, went through a period of barter, in which fisheries resources served as a bargaining chip to obtain agricultural products. Over time, with the emergence of communities, towns and cities, man developed the marketing of these resources. In Brazil, spread rapidly in many regions, by having a coastline that stretches for $8500 \mathrm{~km}$. In Pirambu/SE, we have fishing as the main economic activity of the municipality until the present day and, as in other fishing communities, viewed a strong sexual division of labor. Therefore, aimed to verify the environmental perceptions of fishermen and seafood restaurants in the municipality of Pirambu/SE on the sexual division of labor prevailing in the fishing structure of the city. For this, we used a qualitative approach to the realization of semi-structured interviews. After analyzing the results, it is concluded that the division of labor is strongly bounded but no subordination of women's work, but a naturalization of relations.

Keywords: Environmental. Perception. Sexual Division of Labor. Fishing Activity. 


\section{Apresentação do tema}

\subsection{A Pesca em Pirambu}

A pesca é uma atividade antiquíssima. Inicialmente com caráter de subsistência, passou por um período de escambo, no qual os recursos pesqueiros serviam como moeda de troca para obtenção de produtos agrícolas. Ao longo dos tempos, com o surgimento de comunidades, vilas e cidades, o homem desenvolveu a comercialização destes recursos. No Brasil, a origem da atividade remonta a pré-história (Cardoso, 2009). De acordo com o autor é possível verificar, através dos sambaquis encontrados no litoral, que as populações pré-históricas que residiram em nosso território possuíam uma dieta baseada na pesca e na coleta de frutos do mar.

Outra população que fez uso do rio e do mar para obtenção de alimento foi a indígena. Para Silva (2005) os processos de organização da atividade no país remontam aos tempos pré-coloniais, quando os índios se organizavam em grupos familiares ou de aldeia para a captura de peixes com o objetivo de subsistência. De modo que a extração ocorria dentro dos limites da necessidade imediata dessa população.

A presença ainda hoje de embarcações como a canoa e a jangada, as redes tecidas com fibras vegetais, algumas armadilhas para a captura de pescado e a cestaria empregada nas pescarias atuais, com maior ou menor transformação, revelam a herança deixada pelas diversas nações indígenas na cultura da pesca brasileira (CARDOSO, 2009).

O Brasil possui uma costa marítima que se estende por $8,5 \mathrm{mil} \mathrm{km}$, sua Zona Econômica Exclusiva (ZEE) abrange mais de 4,3 milhões de km² e condições climáticas contribuem para a grande diversidade de espécies animais encontradas em suas águas (LOPES, 2004). Tais características podem explicar o fato de parcela expressiva da população se relacionar com a pesca no país.

De modo geral, a pesca no Brasil pode ser dividida em duas grandes fases: a artesanal ou pré-industrial e a industrial (GIULIETTI e ASSUMPÇÃO, 1995). O marco entre as duas fases foi a criação da Superintendência do Desenvolvimento da Pesca (SUDEPE), que ocorreu em 1967. 
Lopes afirma

A atividade pesqueira está presente no Brasil desde os tempos da colônia ${ }^{2}$. Até a década de 60 , era predominantemente artesanal e sua comercialização destinada basicamente ao mercado interno. Em termos de beneficiamento e industrialização do pescado, o máximo que existia era a salga e algumas poucas iniciativas da indústria do enlatado - caso da sardinha (LOPES, 2004, p. 18).

A pesca industrial começou a se desenvolver a partir da década de 60, voltada, porém, para o mercado externo e graças a uma política de incentivos governamentais. Como consequência, houve uma significativa expansão do parque industrial pesqueiro, em especial a ampliação da indústria de enlatados de sardinha. Posteriormente, indústrias de beneficiamento de outras espécies, como o atum e afins, tiveram também seus parques industriais ampliados.

A pesca industrial caracteriza-se pelo tipo de embarcação empregada (médio e grande porte) e pela relação de trabalho dos pescadores, que diferentemente do segmento artesanal, possuem vínculo empregatício com o armador de pesca (responsável pela embarcação), seja pessoa física ou jurídica (Ministério da Pesca e Aquicultura, 2011). No entanto, essa caracterização não é suficiente para definir a realidade de todos os grupos de pescadores, pois nem sempre o tipo e tamanho da embarcação é uma característica distintiva entre a pesca artesanal e industrial, já que a definição entre as duas modalidades de pesca modifica-se de uma região para outra.

A divisão preconizada pelo MPA está presente em vários estudos, sendo considerados pescadores artesanais aqueles que utilizam embarcações pequenas (como a canoa), com envolvimento familiar ou comunitário, conhecimentos transmitidos pela oralidade, tempo do trabalho regrado pelos ciclos da natureza e mistificação da mesma, bem como a utilização de instrumentos mais rústicos, fabricados pelos próprios pescadores.

Em Pirambu, pode-se considerar a pesca como prioritariamente industrial, fundamentada na produção capitalista de armadores e

${ }^{2} \mathrm{O}$ autor refere-se a atividade pesqueira comercial, iniciada no período colonial brasileiro. 
embarcados (Diegues, 1983) ${ }^{3}$. Contudo, algumas características da pesca artesanal, como a participação familiar ou comunitária e a transmissão de conhecimentos através da oralidade, persistem até hoje.

O panorama da atividade se configura da seguinte maneira:

Pescadores e marisqueiras ${ }^{4}$ estão vinculados à Colônia de pescadores Z-5, situada no município, de modo que todos os filiados possuem os mesmos benefícios trabalhistas e previdenciários que qualquer outro profissional. No entanto, há ainda uma associação, a qual objetiva regular o uso do terminal pesqueiro (administrada pelos armeiros donos de barco) e a Associação de Mulheres Pescadoras de Pirambu AMPAP - recentemente criada, na qual estão associadas somente as marisqueiras. Tal associação ainda não se encontra consolidada.

A pesca ocorre em alto mar e é realizada somente pelos homens, que passam em média de 5 a 15 dias, a depender das condições do mar e do tamanho da embarcação. Contudo, também há a pesca no rio Japaratuba, em menor quantidade e principalmente na época do defeso do camarão ${ }^{5}$. As mulheres, em sua grande maioria não pescam ${ }^{6}$, nem catam mariscos, realizando somente o beneficiamento do pescado, especialmente do camarão.

Tal divisão sexual do trabalho é bastante comum em diversas comunidades pesqueiras. De acordo com Machado (2009),

As mulheres, de modo variado nas comunidades pesqueiras, realizam atividades que envolvem a captura de peixes (a pesca com linha de mão e pequenas redes, coleta de mariscos, a pesca de polvo), o beneficiamento do pescado (a salga do peixe, a evisceração), a manutenção e reparo dos instrumentos de pesca

${ }^{3}$ O presente trabalho adota a classificação de Diegues (1983) por acreditar que seja mais completa, dando ênfase aos diversos aspectos da atividade pesqueira em cada região.

${ }^{4}$ Entende-se por marisqueiras, as mulheres que trabalham na mariscagem, ou seja, que extraem crustáceos e moluscos nas regiões de mangue, áreas estas, situadas na transição entre o ambiente marinho e o terrestre (VASCONCELOS et al., 2012). De acordo com Fadigas (2009), "a marisqueira normalmente trabalha em regime de economia familiar, significando que a atuação laboral de outros membros da família, ou até mesmo a colaboração não onerosa de conhecidos, se torna elemento essencial para o exercício de sua profissão" (p. 99).

5 A pesca no rio Japaratuba aumenta na época do defeso do camarão pela impossibilidade de pesca em alto mar. Qualquer pescador flagrado em território proibido durante este período é multado e tem seu estoque de pescado apreendido.

${ }^{6}$ Quando existem mulheres pescando são para ajudar seus maridos e mesmo assim são poucas. 
(redes, velas de canoa) e a comercialização dos peixes. Entretanto, de modo geral, quando as atividades das mulheres estão relacionadas ao ambiente aquático, elas são realizadas, em geral, nas áreas cuja proximidade se refere à terra (rios, mangues, arrecifes, praia), enquanto que, as atividades realizadas por homens ocorrem em alto mar (MACHADO, 2009, p.4).

Essa divisão sexual de trabalho na pesca é por diversas vezes vista como uma naturalização das relações de trabalho homem-mulher, pois cabe aos homens a realização de tarefas mais difíceis e braçais, que necessitem de mais força e à mulher, tradicionalmente, deve realizar as tarefas de casa e a função de cuidar dos filhos. Desse modo se a mulher trabalha fora de casa, é importante que esteja em um ambiente mais seguro e até próximo de sua residência, lembrando que há o acúmulo com as funções domésticas. Assim, compreende-se a importância do estudo das percepções de pescadores e marisqueiras sobre as relações estabelecidas na atividade pesqueira no município de Pirambu/SE.

\section{Metodologia}

O presente trabalho objetivou verificar as percepções ambientais de pescadores e marisqueiras do município de Pirambu/SE sobre a divisão sexual de trabalho vigente na estrutura pesqueira do município. Para tanto, utilizou-se uma abordagem qualitativa, na qual conforme a visão de Lakatos e Marconi (2009b) "preocupa-se em analisar e interpretar aspectos mais profundos, descrevendo a complexidade do comportamento humano. Fornece análise mais detalhada sobre as investigações, hábitos, atitudes, tendências de comportamento, etc". (p. 269).

Com base em Gil (2006), a pesquisa pode ser classificada como exploratória, pois pretende proporcionar maior familiaridade com o problema, e descritiva, por descrever características de determinada população ou fenômeno.

O estudo das percepções dos participantes, tal como proposto nesta pesquisa, encontra fundamentação na abordagem fenomenológica, a qual de acordo com Merleau-Ponty (2011), "é o estudo das essências" (p. 1). Moreira (2004) afirma que 
$\mathrm{Na}$ aplicação do método fenomenológico a pesquisa, o fenômeno é algum tipo de experiência vivida, comum aos diversos participantes. (...) Os diversos aspectos da experiência, comum a todos os participantes, constituir-se-ão na essência dessa experiência vivida. (p. 114-115).

\subsection{O Estudo da Percepção Ambiental}

Perceber, segundo Houaiss e Vilar (2009, p.1470), “é tomar consciência por meio dos sentidos, captar com a inteligência, compreender". Segundo Penna (1968), pode-se dizer que tradicionalmente a percepção foi entendida como um processo interpretativo dos dados sensoriais. De acordo com este autor, ao entrar em contato com o objeto, os estímulos sensoriais serviriam para uma apreensão de dados isolados, como cheiro, cor e textura. A partir dai, há um processo de significação e organização de tais dados, enriquecidos com a experiência passada do indivíduo. A esse processo damos o nome de percepção.

Sobre tal processo Schiffman, (2005) afirma que sensação e percepção diferenciam-se entre si. A primeira refere-se às experiências "fundamentais", relacionadas à consciência de qualidades do ambiente físico. Já a percepção, refere-se ao resultado da organização e da integração de sensações que levam a uma consciência dos objetos. De acordo com Jorge (2011), as percepções são os resultados dos processos psicológicos ligados à significação e memória das experiências vividas, organizando e integrando os dados obtidos com as sensações. Segundo a autora, a percepção implica significados, relações, contextos, julgamentos, experiências passadas e memória, sendo de um modo geral, a porta de entrada das formas e qualidades do mundo, pois é uma informação recebida e processada pelo indivíduo.

Auth e Meller (2007), afirmam que a percepção que o indivíduo possui sobre algo baseia-se no conhecimento adquirido por suas experiências anteriores. Contudo, segundo Merleau-Ponty (2011), perceber não se resume a captar a presença de um objeto, mas inclui a experiência que se tem a partir deste objeto. O significado virá através da vivência que o indivíduo teve com determinado objeto.

Quando o objeto de percepção é a interação do indivíduo com seu meio, chamamos de percepção ambiental. Para Filho e Fernandes (2010), 
Percepção ambiental é o estudo da relação entre o sujeito e o meio em que ele está inserido. Especificamente, a forma como o sujeito percebe este meio, e a forma como ele se percebe no meio, individual e coletivamente. De forma geral, mas não unânime, são estudos interdisciplinares, pois tem como principal objetivo analisar e explicitar a relação citada valorizando a experiência do sujeito em diferentes situações e sob diferentes aspectos (p. 44).

De acordo com Cordeiro e Santos (2010), a percepção ambiental envolve sentimentos, leitura da realidade, imaginário, representação social, crenças, conhecimentos, cultura e intenções. Todos esses elementos são significativos, pois possuem influência sobre $o$ comportamento humano. Ainda para esses autores, os homens relacionam os conhecimentos adquiridos com a construção de um cenário que promove uma articulação entre os meios natural e social.

O estudo de tais determinantes sociais que operam em nível perceptivo é relativamente recente, pois foram negligenciados por muito tempo (PENNA, 1968), especialmente por serem resultados de aprendizagem. No entanto, tais aspectos ocupam hoje lugar privilegiado nos estudos de percepção e segundo Hochberg (1973), incluem-se como determinantes todos os efeitos de experiências, interesses, recompensas, punições e expectativas passadas. Por esse motivo, espera-se que indivíduos e/ou grupos oriundos de classes ou origens sociais distintas possuam percepções diferenciadas de um mesmo ambiente ou objeto.

Para Tuan (1980), os seres humanos, individualmente ou em grupos, tendem a perceber o mundo tendo o "self" como centro. Cada pessoa perceberá o mundo a sua volta a partir de seus valores, sentimentos e atitudes, mediados pela sua cultura. Todavia, nem sempre o processo se dá de modo individual, pois "as experiências dentro de um grupo humano se superpõem o suficiente para que vínculos individuais não pareçam notórios e incompreensíveis para os seus pares" (TUAN, 1983, p.163).

Segundo Filho e Fernandes (2010)

As características de um grupo de pessoas pertencentes a um mesmo meio social concedem ao indivíduo, membro deste grupo, uma identidade cultural, algo que o torne parte, ou melhor, par, igual. Essa identidade cultural se mostra de diferentes formas, dentre elas através de símbolos que representem ideias em comum (p. 47). 
Com base nisso, corrobora-se com Barreto (2008) que considera cada comunidade possuidora de características singulares, e por esse motivo, o estudo da percepção do ambiente local, torna-se um aliado na preservação do meio ambiente, pois, seus resultados podem auxiliar na construção de ações que levem em consideração os anseios específicos da comunidade em questão.

\section{2. Caracterização da Área de Estudo}

Pirambu (Figura 1) situa-se no litoral norte do Estado de Sergipe, distante da capital $76 \mathrm{Km}$ (pela BR-101) ou $25 \mathrm{Km}$ (pela rodovia SE100 ), ocupando uma área de $218 \mathrm{Km}^{2}$, numa região caracterizada como planície litorânea. Sua topografia apresenta poucas elevações, formadas pelas dunas de areia branca. Possui vegetação litorânea variada, com praias onde predominam coqueiros e uma vegetação rasteira, com campos de dunas, matas de restinga e manguezais. Sua economia é baseada na pesca do camarão e do peixe, sendo um dos maiores centros pesqueiros do Nordeste, exportando para Bahia, Pernambuco, Alagoas, Ceará e Rio Grande do Norte (BRASIL, 2002).

Figura 1 - Mapa do município de Pirambu/SE.

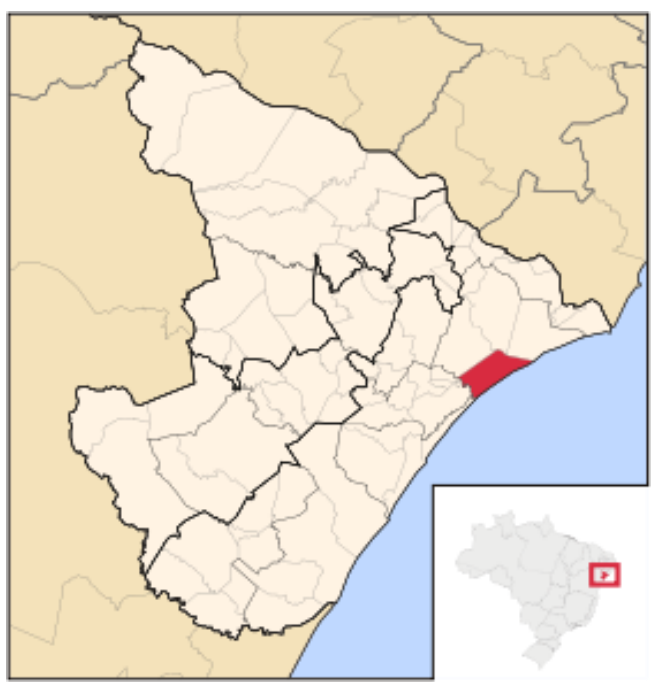

Fonte: Wikipedia ${ }^{7}$

\footnotetext{
${ }^{7}$ http://pt.wikipedia.org/wiki/Ficheiro:Sergipe_Municip_Pirambu.svg
} 
Decretado município pela Lei Estadual № 1.234 de 26 de novembro de 1963, é composto pelos povoados: Lagoa Redonda, Maribondo, Alagamar, Aguilhadas, Aningas, Baixa Grande, Água Boa, Bebedouro e Lagoa Grande (BRASIL, 2010), possuindo, de acordo com o último senso do IBGE (Instituto Brasileiro de Geografia e Estatística), aproximadamente nove mil habitantes distribuídos nas zonas rural e urbana, dos quais 60\% vivem da pesca (BRASIL, 2002).

\section{3. Participantes}

A amostra para essa pesquisa foi composta por dez pescadores e dez marisqueiras.A seleção de poucos entrevistados foi determinada pelas condições de campo e pela disponibilidade dos sujeitos, visto que os pescadores passam muitos dias em alto mar e as marisqueiras apresentaram resistência ${ }^{8}$ em participar da pesquisa. Esse tipo de amostra, não-probabilística, conhecida por "conveniência" é muito utilizada em pesquisas exploratórias, de modo que o pesquisador seleciona os elementos a que tem acesso, admitindo que estes possam representar um universo (MAROTTI et. al., 2008).

\section{4. Procedimento para coleta de dados}

Num segundo momento, foram feitas aplicações de entrevistas semiestruturadas individuais e anotações em diário de campo relacionadas às condições presentes no ambiente de trabalho dos participantes.

Durante a realização das entrevistas seguiu-se um roteiro pré-definido, mas com a liberdade de poder explorar mais amplamente determinadas questões. Os pescadores e marisqueiras foram contatados no entreposto pesqueiro do município, onde podem ser encontrados com maior frequência. As entrevistas foram gravadas, mediante a anuência dos participantes.

Para Lakatos e Marconi (2008) como técnica de coleta de dados, a entrevista oferece várias vantagens, entre elas,

8 Não foi possível detectar o real motivo da resistência apresentada pelas marisqueiras durante a pesquisa, mas algumas suposições podem ser inferidas, pois as mesmas sofrem discriminação pelo cheiro impregnado de pescados em seu corpo, recebem diversos pesquisadores no local e não vêm a efetiva mudança prometida, ou até mesmo para não perder tempo com distrações que a façam ganhar menos. 
Pode ser utilizada com todos os segmentos da população: analfabetos ou alfabetizados; há maior flexibilidade, podendo o entrevistador repetir ou esclarecer perguntas, formular de maneira diferente, especificar algum significado como garantia de estar sendo compreendido; oferece maior oportunidade para avaliar atitudes, condutas, podendo o entrevistado ser observado naquilo que diz e como diz: registro de reações, gestos, etc; dá oportunidade para a obtenção de dados que não se encontram em fontes documentais e que sejam relevantes e significativos; há possibilidade de conseguir informações mais precisas, podendo ser comprovadas, de imediato, as discordâncias (p.83).

É importante frisar que os roteiros das entrevistas passaram por um pré-teste, de modo a evitar problemas de entendimento. Segundo Lakatos e Marconi (2009 - A), “A pesquisa-piloto evidenciará ambiguidade das questões, existência de perguntas supérfluas, adequação ou não da ordem de apresentação das questões, se são muito numerosas ou, ao contrário, necessitam ser complementadas etc" (p.133).

\section{5. Procedimento para análise dos dados}

Após a transcrição das falas registradas nas entrevistas, facilitada pela utilização do programa Express Scribe, procedeu-se a análise das mesmas de acordo com a técnica da Análise de Conteúdo, segundo a visão de Bardin (1977), que a define como:

Um conjunto de técnicas das comunicações visando obter por procedimentos sistemáticos e objetivos de descrição do conteúdo das mensagens indicadores (quantitativos ou não) que permitem a inferência de conhecimentos relativos às condições de produção/recepção (variáveis inferidas) destas mensagens (p. 44).

A análise se deu através da catalogação de todas as respostas dos participantes, em cada questão, seguida da leitura das mesmas visando a identificação de aspectos relacionados à temática da questão. Após a identificação de similaridades e a elaboração de categorias, contou-se a frequência de respostas. Quando houve respostas não diretamente relacionadas à temática da questão, as mesmas foram analisadas à parte. 


\section{Apresentação e discussão dos resultados}

\subsection{Percepção dos pescadores}

A média de idade dos entrevistados foi entre 30-49 anos, revelando um perfil de trabalhadores adultos. De acordo com os pescadores, o distanciamento da atividade pelos jovens refere-se às dificuldades enfrentadas na profissão ${ }^{9}$. Esta afirmação também se configura como a principal razão para explicar porque as mulheres são excluídas da captura do pescado.

Quanto às condições de risco, Andreoli (2007) afirma que o pescador enfrenta muitas situações de risco, não só pelas próprias condições do mar, como também das embarcações utilizadas. Segundo os entrevistados, as principais dificuldades enfrentadas na pesca em Pirambu são os riscos de acidentes e problemas de saúde que ocorrem em alto mar.

Dos dez entrevistados, oito pescadores relataram que a principal dificuldade da profissão é o constante risco de acidentes a que estão expostos em alto mar. Segundo os entrevistados são riscos que variam de leve a grave, como observado nas falas a seguir:

Pescador 3: "Já sofri alguns acidentes (...) O motor do barco já pegou fogo, mas não tive nada e outra vez a catarina caiu em cima de mim”.

Pescador 6: "Me desequilibrei e cai. Mas só quebrei os dentes"

Pescador 7: “A rede enganchou de um jeito que tinha que cortar. Ai eu fui cortar, só que a rede enganchou. Acabei perdendo a cabeça do dedo e tive que fazer cirurgia para enxertar carne de outro lugar”.

Pescador 8: "O barco já virou uma vez, mas não tive nada grave não”.

Quanto aos problemas de saúde, os entrevistados informaram que algumas vezes adoecem enquanto estão embarcados, tornando difícil o cumprimento de suas tarefas. Somente um relatou ter problemas decorrentes da atividade, visualizado na fala abaixo:

\footnotetext{
${ }^{9}$ Existe ainda outro fator responsável pelo afastamento de jovens na profissão e que se refere à própria dinâmica de aprendizagem da pesca, pois é necessário um curso de formação de aquaviários oferecido pela Capitania dos Portos.
} 
Pescador 8: "Tô com um problema no joelho, que tá até precisando operar de tanto forçar. (...) Quando a gente se encosta ali no canto pra puxar a rede, força muito...".

Durante a época do defeso fica proibida a pesca de determinadas espécies que estão em período reprodutivo. Em Pirambu, está parada só ocorre para a pesca do camarão e do caranguejo, bem como em todo o Estado de Sergipe. Neste período, os pescadores recebem um auxílio financeiro, conhecido como seguro-defeso.

A maioria dos pescadores complementa sua renda pescando peixes em canoas a remo, no estuário do rio Japaratuba durante a proibição de ida a alto mar. Tal fato é importante, pois nesse momento algumas mulheres são flagradas ajudando seus maridos na captura do pescado. Tal situação vem a reforçar que a divisão sexual de trabalho em Pirambu ocorre por uma questão de naturalização de relações, onde a mulher precisa ser afastada dos serviços mais perigosos. Como a pesca realizada no estuário do rio é mais calma, admite-se a presença de mulheres.

Os entrevistados não visualizam nenhum ponto positivo na atividade. Segundo eles:

Pescador 9: "De positivo agora o bicho pegou (pausa), o barco sempre quebra, a Petrobrás vem com uma pesquisa nova e empata a pescaria. (...) O barco quando vem do mar, vem com uma margem de lucro boa, mas quando volta pro mar já leva boa parte do dinheiro. Não sobra pra você ter outra coisa, é só pra manter mesmo a casa”.

Pescador 7: "Nem sei dizer do que gosto na pesca...”.

De acordo com os pescadores, só há ponto negativo na atividade, pois ganham pouco, estão sujeitos a diversos riscos e a infraestrutura é precária. Cardoso (2001) afirma que mesmo com todas as dificuldades enfrentadas na profissão, algumas regiões continuam a fornecer pessoas a pesca, porque a entrada na atividade passa a ser a única oportunidade de emprego. 


\subsection{Percepção das marisqueiras}

Embora não extraiam crustáceos e moluscos (conhecidos popularmente como mariscos), as mulheres que trabalham beneficiando o pescado em Pirambu recebem o nome de marisqueiras. São encontrados poucos homens nesta profissão. Normalmente, estão ajudando suas esposas quando não podem ir ao mar ou são seus filhos. Para Vasconcelos et al.

Fica evidente que a desigualdade de gênero é um fator determinante na divisão do trabalho dentro da atividade pesqueira. A predominância da mulher atuando na mariscagem denuncia as relações de dominação que se estabelecem entre homens e mulheres pescadores. A mulher, vista como sexo frágil, "não poderia" se arremessar ao mar em busca do pescado, por ser uma atividade que exige força e impõe riscos, além de exigir um afastamento maior da residência, aspectos historicamente relacionados ao sexo masculino; já a mariscagem preenche os requisitos de uma tarefa socialmente atribuída às mulheres, considerada mais minuciosa, exigindo paciência e cuidado, além de não implicar em maior afastamento do lar. (2012, p. 4)

As marisqueiras entrevistadas são mais novas que os pescadores, possuindo média de idade de 36,4 anos. Tal identificação é importante, pois as mulheres tendem a iniciar mais cedo na profissão, por não exigir nenhum preparo anterior, o trabalho é aprendido na infância pela observação de suas mães ou familiares. Segundo as entrevistadas, todas começaram ainda crianças com suas mães, tias e avós. Àquelas que já possuem filhos adolescentes afirmam que os mesmos já auxiliam na atividade.

Para Gomes (2009), na rotina das mariscagens, as crianças observam o trabalho de suas mães e aprendem as ações próprias da atividade. Sobre esse regime familiar, Fadigas (2009) afirma que as crianças acompanham suas mães durante o trabalho e acabam por repetir suas habilidades como uma brincadeira. Quando crescem e se deparam com a falta de emprego na cidade, em especial as meninas que engravidam jovens, somam-se à mariscagem, desta vez profissionalmente.

Quando questionadas sobre os pontos positivos da profissão, responderam estar satisfeitas por serem autônomas, possuindo liberdade no trabalho. Metade das entrevistadas afirmou que o ponto positivo da atividade é não possuir horário e não ter ninguém 
mandando. Tudo ocorre em seu próprio ritmo, como vemos nas falas listadas abaixo:

Marisqueira 4: "Gosto do trabalho porque não tem quem mande (...) é nosso e a gente trabalha quando quer".

Marisqueira 5: “Gosto porque trabalho pra mim...”.

Para elas a flexibilidade de horário é necessária, pois quando precisam resolver as questões da família ou até mesmo as tarefas de casa ausentam-se do entreposto pesqueiro e não são penalizadas. Não há fiscal.

Pode-se encontrar marisqueiras beneficiando peixes, contudo grande parcela trabalha exclusivamente com camarão. $O$ beneficiamento ocorre de segunda a sexta, nos turnos matutino e vespertino. Segundo as mesmas, se não forem trabalhar só deixam de ganhar mais ao final da semana, quando os atravessadores recolhem os filés de camarão e as pagam $\mathrm{R} \$ 1,00$ por $\mathrm{Kg} /$ beneficiado.

Porém, quando questionadas a respeito dos pontos negativos da atividade, a falta de emprego em outras áreas da cidade foi o mais mencionado. Para elas, a mariscagem é um trabalho difícil, sacrificante e desvalorizado. Reclamam do mau cheiro a que estão expostas e de precisarem carregar peso ${ }^{10}$. Com relação a essa última queixa, ocorre, pois são responsáveis pelo congelamento do filé de camarão e por esse motivo, pegam os isopores com gelo e levam de um lado a outro. A insatisfação das entrevistadas pode ser visualizada nas falas a seguir:

Marisqueira 3: "Não gosto de pegar peso (...) doem as costas, dá um cansaço nas pernas, aparece varizes (...)”.

Marisqueira 10: "Trabalho porque é o jeito. Se não trabalhar não come, mas o ganho é pouco".

Fadigas (2009), em pesquisa com as marisqueiras de Acaú e Carne de Vaca, respectivamente nos estados de Pernambuco e Paraíba,

10 Contraditoriamente ao fato de que os homens seriam os responsáveis pelos trabalhos braçais e mais difíceis, cabe as mulheres a função de carregar os isopores com gelo, de um lado a outro no porto, já que nos mesmos serão congelados os filés de pescado beneficiados por elas. 
encontrou um índice de insatisfação com a realização de seu trabalho bastante alto.

De acordo com Vasconcelos et. al. (2012), há uma imagem de subordinação e desvalorização da atividade, a qual é encarada como uma tarefa que apenas complementa a renda familiar, encontrando-se no mesmo patamar de "desprestígio social" que as demais atividades domésticas. No entanto, para Gomes (2012), tal situação não constitui uma subordinação do trabalho feminino, mas uma naturalização dessas relações. Em Pirambu, presencia-se o entendimento de naturalização das relações, não só pelos pescadores mas também pelas marisqueiras, que não se enxergam subordinadas aos pescadores e atravessadores.

\section{Considerações finais}

É forte a divisão sexual de trabalho encontrada em Pirambu, de modo que os homens são responsáveis pela captura do pescado, seja em alto mar ou no rio, e às mulheres cabe o beneficiamento do mesmo, sendo um trabalho considerado "inferior". Tal fato pode ser verificado através da discriminação as quais estão sujeitas por ficarem com o cheiro do pescado impregnado em suas roupas e em suas mãos.

Embora se possa dizer que há uma desvalorização do trabalho feminino na pesca em Pirambu, não se pode afirmar que haja uma subordinação das relações, pois se verificou uma naturalização das relações de trabalho, inclusive pelas próprias marisqueiras, que não se visualizam subordinadas aos pescadores e atravessadores ${ }^{11}$.

Tal fato pode ser explicado pela presença de um conformismo baseado na tradição. Exemplo disso é que os pescadores, bem como as marisqueiras falam de seus próprios trabalhos como algo difícil, massacrante, de modo que em nenhum momento um se sobrepuja ao outro. Assim, conclui-se que em Pirambu é forte a divisão sexual de

\footnotetext{
${ }^{11}$ Quando diz-se que as marisqueiras não se sentem inferiores quanto às relações de trabalho, é necessário compreender que para elas a situação segue uma ordem natural, decorre da ordem regular das coisas. Porém, tal sentimento não anula o fato de serem subordinadas nestas mesmas relações trabalhistas, pois há a dependência das mesmas em relação a outras pessoas, em especial ao atravessador (Houaiss e Vilar, 2009).
} 
trabalho na atividade pesqueira, mas a mesma ocorre de maneira natural entre os sujeitos envolvidos.

\section{Referências}

ANDREOLI, V. Natureza e pesca: um estudo sobre os pescadores artesanais de matinhos. Dissertação do programa de pós-graduação em Sociologia. Universidade Federal do Paraná. Curitiba, 2007.

AUTH, M.; MELLER, C. Ser humano e ambiente: percepção e interação. 2. Ed. Ijuí: Ed. Unijuí, 2007. (Coleção Situação de Estudo. Ciências no Ensino Fundamental).

BARDIN, L. Análise de conteúdo. Lisboa: edições, 1977.

BARRETO, K. F.B. Impactos da intervenção do projeto "doces matas" em comunidades de mata atlântica: perspectiva de um estudo de percepção ambiental.Dissertação (Mestrado em Desenvolvimento e Meio Ambiente) - Núcleo de Pós-Graduação em Desenvolvimento e Meio Ambiente, Programa Regional de Desenvolvimento e Meio Ambiente, Pró-Reitoria de Pós- Graduação e Pesquisa, Universidade Federal de Sergipe, São Cristóvão, 2008.

BRASIL. Ministério de Minas e Energia. Projeto cadastro da infraestrutura hídrica do nordeste - estado de Sergipe. Diagnóstico do município de Pirambu.Aracaju, 2002.

Ministério do Meio Ambiente. Proposta de retificação e atualização dos limites da reserva biológica de Santa Isabel, no estado de Sergipe - relatório técnico.Pirambu, 2010.

CARDOSO, E. Pescadores artesanais: natureza, território, movimentos sociais. Tese de doutorado, Universidade de São Paulo, São Paulo, 2001.

Trabalho e pesca: apontamentos para a investigação. Revista Pegada, vol. 10 n.2, dezembro/2009.

CORDEIRO, J. ; SANTOS, J. Práticas Educativas e o Meio Ambiente: a questão da água doce no mundo. In: ABÍLIO, F. (org.). Educação 
ambiental e ensino de ciências. João Pessoa: Editora Universitária da UFPB, 2010.

DIEGUES, A. Pescadores, camponeses e trabalhadores do mar. São Paulo: Ática, 1983.

FADIGAS, A. As marisqueiras e a reserva extrativista Acaúgoiana: uma análise de práticas participativas para a conservação do ambiente. Dissertação (Mestrado em Desenvolvimento e Meio Ambiente) - Núcleo de Pós-Graduação em Desenvolvimento e Meio Ambiente, Programa Regional de Desenvolvimento e Meio Ambiente, Pró-Reitoria de Pós- Graduação e Pesquisa, Universidade Federal da Paraíba, João Pessoa, 2009.

FILHO, C.; FERNANDES, J. Percepção ambiental: as transformações no cotidiano de caiçaras de Ubatuba-SP na década de 1960 e na primeira década do século XXI. Curitiba: CRV, 2010.

GIL, A. Como elaborar projetos de pesquisa. 4. ed. São Paulo: Atlas, 2006.

GIULIETTI, N.; ASSUMPÇÃO, R. Indústria pesqueira no Brasil. Agricultura em São Paulo, São Paulo, 42(2):95-127, 1995.

GOMES, R. A vida no vai-e-vem das águas: mulheres marisqueiras de salinas da margarida trabalho, cultura e meio ambiente (19601990). Dissertação (Mestrado em História Regional e Local) - Núcleo de Pós-Graduação em História Regional e Local, Universidade do Estado da Bahia -UNEB. Santo Antônio de Jesus, 2009.

HOCHBERG, J. Percepção. São Paulo: Zahar editores, 1973.

HOUAISS, A.; VILAR, M. Dicionário Houaiss da língua Portuguesa. Rio de Janeiro: Objetiva, 2009.

JORGE, A. Introdução a percepção: entre os sentidos e o conhecimento. São Paulo: Paulus, 2011. (Coleção Temas de Comunicação).

LAKATOS, E.; MARCONI, M. Metodologia científica. 5. ed.. - São Paulo: Atlas, 2009a. 
Metodologia do trabalho científico: procedimentos básicos, pesquisa bibliográfica, projeto e relatório, publicações e trabalhos científicos. 7. ed. São Paulo: Atlas, 2009.

Técnicas de pesquisa: planejamento e execução de pesquisas, amostragens e técnicas de pesquisa, elaboração, análise e interpretação de dados. 7. ed. São Paulo: Atlas, 2008.

LOPES, F. O conflito entre a exploração offshore de petróleo e a atividade pesqueira artesanal. Monografia do curso de Economia. Universidade Federal do Rio de Janeiro - Instituto de Economia. Rio de Janeiro, 2004.

MACHADO, M. Entre a terra e o mar: o trabalho das mulheres nas comunidades pesqueiras no Brasil. Alagoas, 2009. Disponível em www.psicologia.com.pt. Acessado em 28 de outubro de 2011.

MAROTTI, J. et. al. Amostragem em pesquisa clínica: tamanho da amostra.Revista de Odontologia da Universidade Cidade de São Paulo, 2008.

MERLEAU-PONTY, M. Fenomenologia da percepção. 4 ed. São Paulo: Editora: WMF Martins Fontes, 2011.

MINISTÉRIO DA PESCA E AQUICULTURA. Disponível em http://www.mpa.gov.br/. Acessado em 21 de maio de 2012.

MOREIRA, D. O método fenomenológico na pesquisa. São Paulo: Pioneira Thomson Learning, 2004.

PENNA, A. Percepção e realidade: introdução ao estudo da atividade perceptiva. Rio de Janeiro: Editora Fundo de Cultura, 1968.

SCHIFFMAN, H. Sensação e percepção. Rio de Janeiro: LTC, 2005.

SILVA, A. A organização social da colônia de pescadores de imperatriz zona 29 (cpi z-29), estado do Maranhão. Dissertação do programa em Planejamento do Desenvolvimento da Universidade Federal do Pará. Belém, 2005.

TUAN, Y. Topofilia: um estudo da percepção, atitudes e valores do meio ambiente. São Paulo: Difel, 1980. 
VASCONCELOS, L. et. al. Trabalho, meio ambiente e saúde em comunidades marisqueiras de Sergipe. Anais do VI Colóquio Internacional "Educação e Contemporaneidade", São Cristóvão Sergipe, 20 a 22 de setembro de 2012. 